Technological University Dublin ARROW@TU Dublin

\title{
Workshop on methodology in learning analytics (MLA)
}

\author{
Yoav Bergner \\ New York University \\ Charles Lang \\ Columbia University \\ Geraldine Gray \\ Technological University Dublin, geraldine.gray@tudublin.ie
}

Follow this and additional works at: https://arrow.tudublin.ie/ltcoth

Part of the Education Commons

\section{Recommended Citation}

Yoav Bergner, Charles Lang, and Geraldine Gray. 2017. Workshop on methodology in learning analytics (MLA). In Proceedings of the Seventh International Learning Analytics \& Knowledge Conference (LAK '17). Association for Computing Machinery, New York, NY, USA, 500-501. DOI: 10.1145/3027385.3029427

This Other is brought to you for free and open access by the Learning Teaching \& Assessment at ARROW@TU Dublin. It has been accepted for inclusion in Other resources by an authorized administrator of ARROW@TU Dublin. For more information, please contact arrow.admin@tudublin.ie, aisling.coyne@tudublin.ie, gerard.connolly@tudublin.ie.

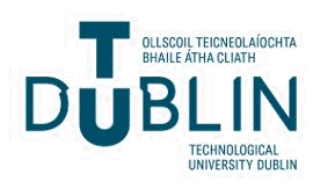




\section{Workshop on Methodology in Learning Analytics (MLA) \\ Yoav Bergner \\ New York University \\ New York, NY, USA \\ yoav.bergner@nyu.edu

\author{
Charles Lang \\ Teachers College, Columbia \\ University \\ New York, NY, USA \\ charles.lang@tc.columbia.edu
}

\author{
Geraldine Gray \\ Institute of Technology, \\ Blanchardstown \\ Dublin, Ireland \\ geraldine.gray@itb.ie
}

\begin{abstract}
Learning analytics is an interdisciplinary and inclusive field, a fact which makes the establishment of methodological norms both challenging and important. This community-building workshop intends to convene methodology-focused researchers to discuss new and established approaches, comment on the state of current practice, author pedagogical manuscripts, and co-develop guidelines to help move the field forward with quality and rigor.
\end{abstract}

\section{CCS Concepts}

- Computing methodologies $\rightarrow$ Modeling and simulation $\rightarrow$ Model development and analysis

\section{Keywords}

Models; Methodology; Measurement; Statistics; Evaluation.

\section{WORKSHOP BACKGROUND}

Learning analytics is an interdisciplinary and inclusive field that brings together educational technologists, psychologists, data scientists, learning scientists, substantive experts in various domains, and measurement specialists [7]. For all of the strength that comes from such diversity, there are also potential pitfalls when it comes to establishing norms for methodological work. For example, Clow [3] described learning analytics as, "a 'jackdaw' field of enquiry, picking up 'shiny' techniques, tools and methodologies... This eclectic approach is both a strength and a weakness: it facilitates rapid development and the ability to build on established practice and findings, but it - to date-lacks a coherent, articulated epistemology of its own.” (p. 686).

In the years since this observation, the learning analytics community has grown rapidly, and the number of shiny techniques has grown as well. Looking just at the last two

\footnotetext{
Permission to make digital or hard copies of part or all of this work for personal or classroom use is granted without fee provided that copies are not made or distributed for profit or commercial advantage and that copies bear this notice and the full citation on the first page. Copyrights for third-party components of this work must be honored. For all other uses, contact the Owner/Author.

Copyright is held by the owner/author(s).

LAK '17, March 13-17, 2017, Vancouver, BC, Canada

ACM 978-1-4503-4870-6/17/03.

http://dx.doi.org/10.1145/3027385.3029427
}

proceedings of the International Conference on Learning Analytics and Knowledge (LAK) in 2015 and 2016, the variety is staggering. Methods range from descriptive statistics to correlation analyses, classification, clustering, regression, (M)AN(C)OVA, structural equation modeling, item response theory, hidden Markov models, time-series analysis, latent semantic analysis, social network analysis, and the list goes on. It is understandable and even expected that reviewers and readers of learning analytics manuscripts are unlikely to be expert evaluators of the methodological rigor in all of these cases.

There is a naturally occurring process of specialization in any academic field. However, if growth of adoption outpaces systematic specialization then there is a risk that methodological errors will proliferate and that quality of community products will suffer.

To make matters even more complex, a number of recent papers have emphasized the sensitivity of quantitative analyses to data collection and variable operationalization choices, for example with regard to effects of selection bias [2], results of time-on-task analyses [4], studies of discussion forum usage [1], and evaluation of student models [6]. In addition, learning analytics models often incorporate a selection of proxy variables as indicators of latent constructs, such as learning and engagement. What proxy variables actually measure is less clear. For example, measures of engagement may be influenced by instructional conditions [5], adding ambiguity, and a lack of consistency, to our interpretation of models of learning.

In short, methodological concerns can arise from a range of practices including but not limited to selecting inappropriate methods, misusing methods, inadequate model evaluation or model comparison, sensitivity to operationalization, and overreliance on proxy variables. As the learning analytics community matures, it is particularly important to establish standards for good practice and to educate new students in accordance with these standards. Clear methodological guidelines increase the quality of work and facilitate communication not only within the community but also with practitioners in other research communities, where norms may be clearer. This is a challenging problem in large part because of the aforementioned diversity of approaches. The present workshop seeks to build a community of researchers with an interest in methodology and its rigorous application and development to the field of learning analytics.

There have been several previous LAK workshops and tutorials that have focused on specific methodologies - a limited set of examples includes the tutorials for classification and clustering using Weka (2014, 2016), special topics in discourse analysis (2013-2014) and writing analysis (2016), and a recurring workshop on temporal analysis (2012-2016) - but not on crosscutting methodological issues such as developing methodological 
frameworks within learning analytics, framing and prioritizing methodological issues for the community, and providing resources to move the field forward.

\section{WORKSHOP OBJECTIVES 2.1 Solicit Papers about Learning Analytics Methodology}

The first objective of the present workshop is to solicit new substantive papers specializing on methodology. We imagine these papers to fall roughly into the following categories: papers presenting new methods or adaptation/modification of methods; position papers which take a critical look at methodological practice in the community; and pedagogical/instructional papers oriented at students or researchers who are new to the field or developing an interest in a particular methodology.

We encourage the exploration of new metrics that are indigenous to learning analytics, papers that link metrics to the latent variable(s) they measure, with a view to establishing definitions of latent variables of relevance to learning analytics, and guidelines on associating observable metrics with latent variables. Papers on appropriate metrics for model evaluation and metrics for comparison of model results where multiple models are reported on would also exemplify an effort to add rigor to applicable studies.

\subsection{Develop Community Guidelines}

Related to the position and instructional papers that may be presented during the workshop, a second objective of convening will be to cooperatively develop community guidelines regarding the uses of various methods including data acquisition, data analysis and evaluation of results in conference and journal publications. Up for discussion will be content, process, and dissemination protocols.

\subsection{Provide Expertise for Review Panels}

A third objective of the workshop is to take responsibility for maintaining a database of methodology experts who are active in the learning analytics community. The expert listing is by no means intended to be exclusionary or to promote certain researchers over others but rather to help community members and editorial committees find methodology experts who are willing to consult and/or review relevant work.

\subsection{Community Building}

Last but not least, an objective of the workshop is to provide a meeting place for researchers who take a special interest in methodological issues. We anticipate that a concentrated meeting will promote continuing collaboration on this important topic.

\section{REFERENCES}

[1] Bergner, Y., Kerr, D., and Pritchard, D. E. 2015. Methodological Challenges in the Analysis of MOOC Data for Exploring the Relationship between Discussion Forum Views and Learning Outcomes. Proceedings of 8th International Conference on Educational Data Mining, 234241.

[2] Brooks, C., Chavez, O., Tritz, J., and Teasley, S. 2015. Reducing selection bias in quasi-experimental educational studies. Proceedings of the Fifth International Conference on Learning Analytics And Knowledge, - LAK '15, ACM Press, 295-299.

[3] Clow, D. 2013. An overview of learning analytics. Teaching in Higher Education 18 (6), 683-695.

[4] Kovanović, V., Gašević, D., Dawson, S., Joksimović, S., Baker, R.S.J.D., and Hatala, M. 2015. Penetrating the black box of time-on-task estimation. Proceedings of the Fifth International Conference on Learning Analytics And Knowledge - LAK '15, ACM Press, 184-193.

[5] Gašević, D., Dawson, S., and Siemens, G. 2015. Let's not forget: Learning analytics are about learning. TechTrends 59 (1), 64-71.

[6] Pelánek, R., Rihák, J., and Papoušek, J. 2016. Impact of data collection on interpretation and evaluation of student models. Proceedings of the Sixth International Conference on Learning Analytics \& Knowledge, - LAK '16, ACM Press, 40-47.

[7] Siemens, G. and Gasevic, D. 2012. Guest Editorial-Learning and Knowledge Analytics. Educational Technology \& Society 15 (3), 1-2. 